\title{
Leprosy: current situation, clinical and laboratory aspects, treatment history and perspective of the uniform multidrug therapy for all patients*
}

\author{
Rossilene Conceição da Silva Cruz ${ }^{1}$ \\ Maria Lúcia F. Penna ${ }^{3}$ \\ Sinésio Talhari'i,
}

\author{
Samira Bührer-Sékula ${ }^{2}$ \\ Gerson Oliveira Penna ${ }^{4,5}$
}

DOI: http:/ /dx.doi.org/10.1590/abd1806-4841.20176724

\begin{abstract}
In this review, the most relevant and current epidemiological data, the main clinical, laboratory and therapeutical aspects of leprosy are presented. Detailed discussion of the main drugs used for leprosy treatment, their most relevant adverse effects, evolution of the therapeutic regimen, from dapsone as a monotherapy to the proposed polychemotherapy by World Health Organization (WHO) can be found in this CME. We specifically highlight the drug acceptability, reduction in treatment duration and the most recent proposal of a single therapeutic regimen, with a fixed six months duration, for all clinical presentations, regardless of their classification.
\end{abstract}

Keywords: Combined modality therapy; Drug combinations; Leprosy; Therapeutics

\section{INTRODUCTION}

Leprosy is an infectious and contagious chronic disease, caused by Mycobacterium leprae, an obligate intracellular bacillus, that affects mainly the skin, nerves and mucous membranes. ${ }^{1,2}$ It can also affect the eye, nose, joints, lymph nodes, internal organs and bone marrow, especially in multibacillary patients $(\mathrm{MB}){ }^{1,2}$ In the majority of cases, it is transmitted from person to person through contact with patients that have a high bacillary index and haven't been treated. ${ }^{1,2}$ In 2008, a new species of mycobacterium was identified in Mexican MB patients - Mycobacterium lepromatosis. ${ }^{3}$ Recently, M. lepromatosis was also found in paucibacillary patients. ${ }^{4}$

The disease has a 2- to 5-year course for paucibacillary patients and a 5- to 10-year course for multibacillary patients. ${ }^{5} \mathrm{Hu}-$ mans are the main natural reservoir of the bacillus. There are reports of armadillos and squirrels naturally infected by M. leprae, with the hypothesis formulation that some cases could have been a consequence of contact with animals, in particular the armadillo..$^{6-9} \mathrm{MB}$ patients are considered the main source for infection in transmission cycle. Although there is evidence of the presence of $M$. leprae in skin lesions, breast milk, environment and animals, the main route of transmission for $M$. leprae is the respiratory tract. ${ }^{2,10,11}$ During disease evolution, reactions might occur that, without propper treatment, can lead to severe damage in the peripheral nerve trunks, originating physical disabilities and sequelae, the main reason for the stigmatization caused by the disease. ${ }^{12}$

\section{DEFINITION OF A LEPROSY CASE}

A person is considered suspicious for leprosy whenever they present with one or more of the following signs or symptoms: pale or reddish patches on the skin; loss, or decrease, of feeling in the skin patches; numbness or tingling of the hands or feet; weakness of the hands, feet or eyelids; painful or tender nerves; swelling of or lumps in the face or earlobes; painless wounds or burns on the hands or feet. ${ }^{11}$

A case of leprosy is defined in every patient that presents with at least one of the following manifestations:

- definite loss of sensation in a pale (hypopigmented) or reddish skin patch;

- a thickened or enlarged peripheral nerve, with loss of sensation and/or weakness of the muscles supplied by that nerve;

- the presence of acid-fast bacilli in a slit-skin smear. ${ }^{11}$

Received on 07.05.2017.

Approved by the Advisory Board and accepted for publication on 23.07.2017.

* Work performed Fundação de Dermatologia Tropical e Venerologia Alfredo da Matta, (FUAM) - Manaus (AM), Brazil. Financial support: None

Conflict of interests: None

Fundação de Dermatologia Tropical e Venereologia "Alfredo da Matta" (FUAM) - Manaus (AM), Brazil.

Post-Graduation Program in Tropical Medicine, Instituto de Patologia Tropical e Saúde Pública, Universidade Federal de Goiás (UFG) - Goiânia (GO), Brazil. Department of Epidemiology and Statistics, Universidade Federal Fluminense (UFF) - Niterói (RJ), Brazil.

Tropical Medicine Center, Universidade de Brasília (UnB) - Brasília (DF), Brazil.

Escola Fiocruz de Governo, Fundação Oswaldo Cruz (EFG-Fiocruz) - Brasília (DF), Brazil.

Discipline of Dermatology, Universidade Nilton Lins - Manaus (AM), Brazil.

Post-Graduation Program of the Fundação de Medicina Tropical and Universidade do Estado do Amazonas (UEA/FMT-HVD) - Manaus (AM), Brazil. 


\section{EPIDEMIOLOGY OF LEPROSY}

The introduction of the multidrug therapy (MDT) or polychemotherapy, recommended by WHO in 1981, led to significant changes in leprosy epidemiology. ${ }^{13}$ Obviously, the reduction in treatment duration, impacted on the prevalence; from over 5 million cases in the 1980s, there was a reduction to less than 200,000 cases in $2015 .{ }^{13-15}$ Graph 1 shows the global prevalence rates of leprosy detection for the period between 2002 and 2015. The excessive optimism with the global reduction of disease prevalence, led WHO, without robust evidence, to establish the global goal of leprosy elimination as a public health issue in 1991, meaning less than one person affected per 10,000 inhabitants. ${ }^{16}$ With this prevalence rate, it was believed that leprosy transmission would be reduced and the disease would naturally disappear.

Prevalence is decreasing in many countries, however the detection rates remain the same in some areas. In 2015, all over the world, 210,758 new cases of leprosy were detected, corresponding to the detection coefficient of 3.2 cases per 100,000 inhabitants and prevalence of $0.29 / 10,000$ inhabitants. The global current data indicates that leprosy elimination goal was achieved. ${ }^{14}$ Of all new cases, 18,796 were in persons under 15 years of age $(8.9 \%$ of the detected patients) and 271 presented with grade 2 disability. In Brazil, of the total 28,761 diagnosed patients, 2,113 (4.46\%) were under 15 years of age. The current proportion of new leprosy cases in individuals under 15 years of age indicates that disease transmission is still significant in the majority of endemic countries, including Brazil.

Current epidemiological data should be interpreted cautiously, since the elimination goals for the year 2000, and 2005 thereafter, were achieved through: changes in the definition of paucibacillary case, single dose treatment for PBs patients with a single lesion, reduction of treatment duration for 24 and 12 months thereafter. As, after finshing the scheduled tretament, the patient is removed from the data. ${ }^{13,17-19}$ There has been marked reduction on leprosy prevalence after MDT introduction and decreased in treatment length; however, this therapeutic regimen have had no impact on transmission. ${ }^{20}$ It is still necessary to improve early detection of cases, prevention measures for disabilities, trainning of health professionals, stimulate research for better understanding of disease transmission, newdrugs and new therapeutical regimens, in order to cease the transmission cycle. ${ }^{21}$

Leprosy elimination took a wrong path, and the goals were proposed without solid scientific evidence that would grant them appropriate support. ${ }^{22-24}$ Brazil, an endemic country, occupies the second place in world absolute number of cases. Prevalence rate in 2015 was $1.01 / 10,000$ inhabitants, with 20,702 cases in the active registry. The detection rate was of $14.7 / 100,000$ inhabitants, with 28,761 new diagnosed cases. ${ }^{25}$ Among Brazilian regions, in 2015, the Midwest had the highest prevalence rate: 3.29/10,000 inhabitants, with 4,465 cases in the active registry. The Northern region had 3,501 patients in active registry and prevalence of 2.0/10,000 inhabitants. Northeast prevalence was $1.58 / 10,000$, with 8,951 cases in the active registry. The prevalence in the Southeast was of $0.34 / 10,000$; with 2,920 cases in the active registry. The lowest prevalence was seen in the Southern region, with $0.29 / 10,000$ inhabitants and 856 cases in the active registry. ${ }^{25}$

\section{CLINICAL CLASSIFICATION}

The many clinical manifestations of leprosy are related to the host cellular immune response. Among the cutaneous manifestations, generally, the indeterminate form is accepted as leprosy initial presentation.

In 1941, Rabello was one of the first to establish the concept of leprosy polar forms. Individuals with indeterminate leprosy (I), untreated, evolved to tuberculoid (T) polar form or to the lepromatous $(\mathrm{L})$ pole, depending on the immune response to $\mathrm{M}$. leprae. ${ }^{25} \mathrm{At}$ the 1953 Congress of Leprosy, that took place in Madrid, the criteria proposed by Rabello were maintained and a new group of patients was added, named by English specialists as borderline (B). In Portuguese and Spanish-speaking countries, the term borderline was translated as dimorphic. This clinically unstable group throughout its course is characterized by manifestations that do not fit in the polar forms. ${ }^{26}$ The best denomination would be interpolar, for these patients do not simply present with the two polar forms of the disease. Clinically, they can present with features close to the T or $\mathrm{L}$ poles, and also intermediate forms.

In the 1960s, Ridley and Jopling proposed modifying Madrid's classification, based on the histological and immunological aspects subdividing borderline (B) patients into borderline-tuberculoid (BT), borderline-borderline (BB) and borderline-lepromatous (BL). This classification is essential in research. In the majority of cases, the initial clinical manifestation of these patients is also indeterminate leprosy. ${ }^{27}$

In general, patients with I, T and BT leprosy have negative

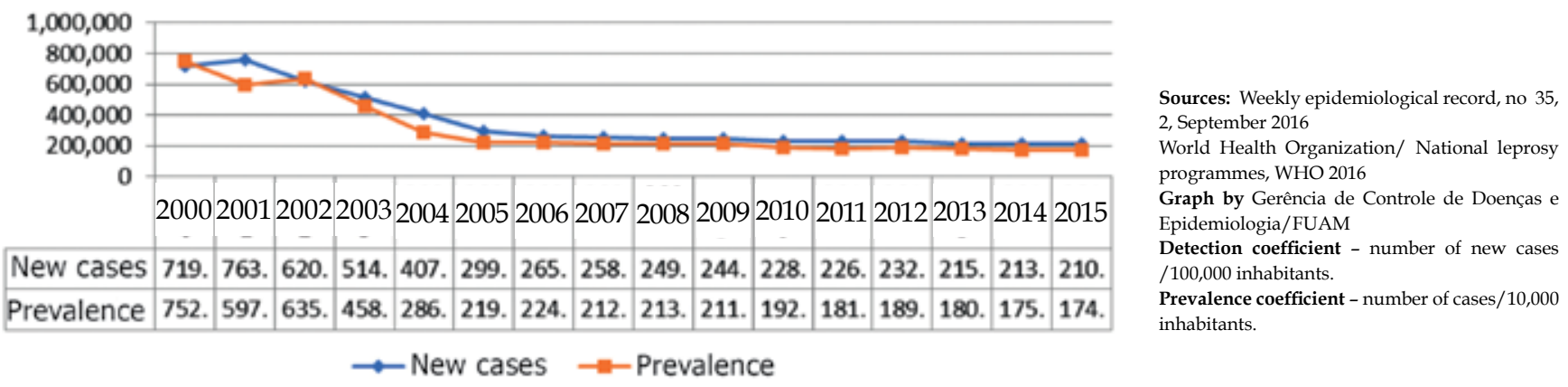

GraPH 1: Global detection and prevalence rates (2000-2015) 
or weakly positive bacilloscopy; $\mathrm{BB}, \mathrm{BL}$ and $\mathrm{L}$ have positive bacilloscopy. Bacilloscopy results are given in: bacteriological index (BI) - from 1+ to 6+, according to the Ridley logarithmic scale; and morphological index (MI) - the presentation of M. leprae as intact, fragmented, or granular. The intact bacillus is considered the viable form.

With the aim to facilitate the implementation of MDT in primary care, WHO changed the classification criteria of leprosy many times. In 1982, they recommended classifying patients into paucibacillary (PB) and multibacillary (MB). ${ }^{13}$ In the PB group, patients with I, T and BT leprosy (BTL), with bacilloscopic index lower than $2+$ are included; $\mathrm{MB}$ include patients with the L, BB, BL and BT clinical forms, with bacilloscopic index $\geq 2$.

In 1987, patients with negative bacilloscopy started to be considered paucibacillary; and cases with positive bacilloscopy, multibacillary, regardless of the BI. ${ }^{28}$ In 1995, there was a new change: WHO recommended the operational classification, according to the number of skin lesions - PB when up to five lesions and MB when there were more than five lesions. ${ }^{29}$ In this classification, there is a risk of misclassication of multibacillary cases as paucibacillary and vice-versa. In 1998, a three classification groups was suggested: PB with single lesion, PB with 2 to 5 lesions and MB with more than 5 lesions. ${ }^{30}$ The classification according to the number of lesions is important for the operationalization of the MDT in primary care facilities. However, when possible, it is important to correctly classify the patient through bacilloscopy and, if necessary, performing biopsy or other complementary tests. Bacilloscopy is essential for appropriate follow-up and is particularly useful in cases where there is suspicion of treatment failure or leprosy reaction.

\section{CLINICAL MANIFESTATIONS}

Indeterminate leprosy (IL) is characterized by hypopigmented lesions, with ill-defined borders when compared to normal skin. The number of lesion is variable and depends on the patient cellular immune response. In the majority of cases, the only change is in temperature perception (Figure 1). Presence of erythema and/ or infiltration of lesions indicate evolution to other clinical forms. Changes in pain and/or touch sensation also indicate evolution. In $\mathrm{IL}$, there is no peripheral nerves thickening. The greater the number of lesions, the worse the prognosis will be if no appropriate treatment take place. Bacilloscopy is negative and on histopathology, there is a nonspecific, mainly perianexial and peri and/or intraneural inflammatory infiltrate. Cases of IL are few in clinical setting. ${ }^{2,12}$

Tuberculoid leprosy (TL) usually presents with a small number of lesions. Hypopigmented or erythematous-hypopigmented numb lesion(s) can be observed. Tinea-like lesions, with well-defined borders when compared to the normal skin are the typical clinical presentation of TL. The center of these lesions can be atrophic, depending on disease duration (Figure 2). Local hair loss is common in old lesions. Temperature, pain, and touch sensation are altered in the majority of cases. Nerve trunks can be involved in TL, usually in a small number. The nerve injury can be very severe, relating to pseudo-abscesses and nerve dysfunction. Bacilloscopy is negative and on histopathology, there are tuberculoid granulomas. ${ }^{2,27}$

Lepromatous leprosy (LL) in its initial phase, is character- ized by erythematous-hypopigmented slightly edematous macules. The edges can progressively became indistinct in relation to the normal skin, increase in size and coalesce, forming extensive edematous areas, that can be disseminated or generalized. Papules and nodules (hansenomas or lepromas) can appear on the edematous areas (Figures 3 and 4). Madarosis, xerosis, edema of the extremities and cyanosis of the palmar and plantar regions can be found. These manifestations are generally bilateral and symmetrical. Thickening of peripheral nerves with bilateral loss of sensibility, in "boot" or "glove", and ocular abnormalities are also common. ${ }^{2,27}$ Cutaneous ulcers, plantar trophic ulcers with bone loss, severe eye manifestations and systemic manifestations can occur in LL patients without appropriate treatment.

Borderline leprosy (BL) group is statistically the largest one in number of diagnosed patients, when clinical and laboratory criteria are correctly applied. In our setting, the term "dimorphic" has also been used to refer to these cases. As previously seen, this term is incorrect, because usually, two forms of leprosy are not seen at the same time. In practice, we keep the English word bordeline, classifying the patients as borderline-tuberculoid (BT), borderline-borderline (BB) and borderline-lepromatous (BL). ${ }^{27}$

From the clinical, laboratory and immunological point of view, patients in the BT group are close to TL. In general, BT patients present erythematous plaques, with varying size and number, and the bacilloscopy is negative or weakly positive (Figure 5A). The typical clinical manifestation of BB patients is the presence of multiple hypopigmented macules of the initial phase (indeterminate) and peripheral iron-red colored edema, affecting the normal skin, and leaving hypopigmented areas with seemingly normal aspect in the center. This clinical presentation is known as "Swiss cheese" aspect

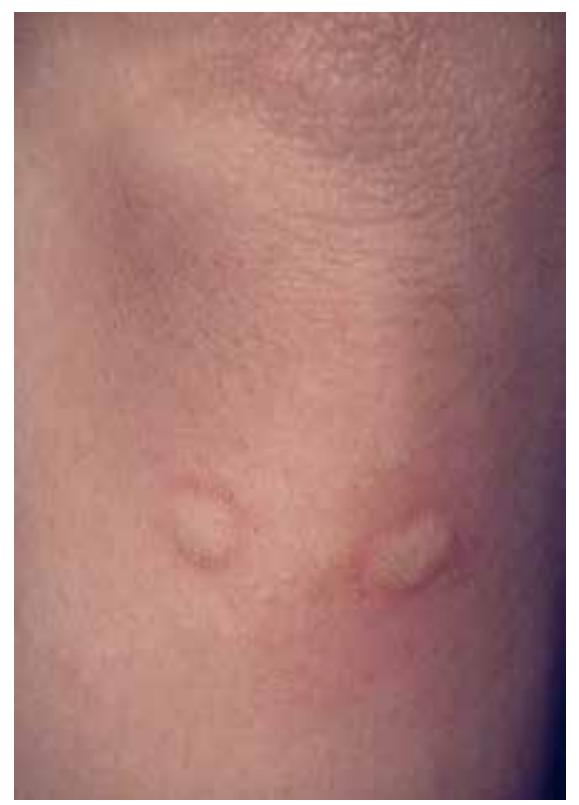

FIgURE 1: Indeterminate leprosy. Hypopigmented macule with ill-defined borders. Altered temperature sensation. Histamine test was incomplete in the center of the lesion and complete in the normal skin

Source: Photo by Dilivros Editora. Talhari S et al., $2015 .{ }^{2}$ 
(Figure 5B). Many other dermatological components, many times similar to those found in LL, can appear as well. The rustycopper? color of the majority of the edematous lesions is common in BBL. Clinically, BLL patients are similar to LL in its different evolutionary phases; however, in the initial and intermediate phases, many areas of normal skin along the infiltrations are seen; lesions similar to BBL are also found (Figure 5). With time, and without treatment, these patients evolve to clinical pictures almost indistinguishable from LL. Bacilloscopy is strongly positive. ${ }^{2,27}$

In all BL patients, the involvement of peripheral nerve trunks are common. Without appropriate treatment and care, there is risk for severe and incapacitating nerve lesions, especially during reactions. ${ }^{31,32}$

Leprosy reactions constitute an important clinical aspect, especially in MB patients. They are characterized by acute episodes

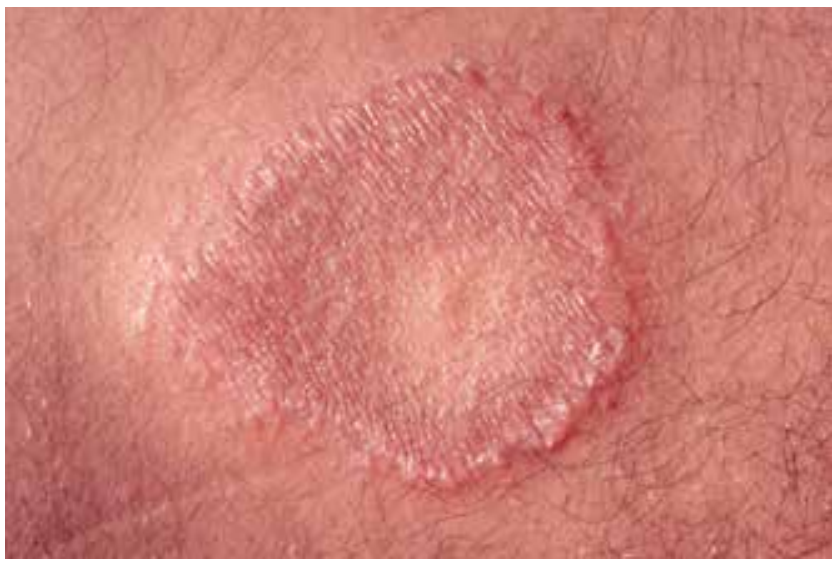

FiguRE 2: Tuberculoid leprosy. Altered temperature and touch sensation. Negative bacilloscopy

Source: Photo by Dilivros Editora. Talhari S et al., 2015. ${ }^{2}$

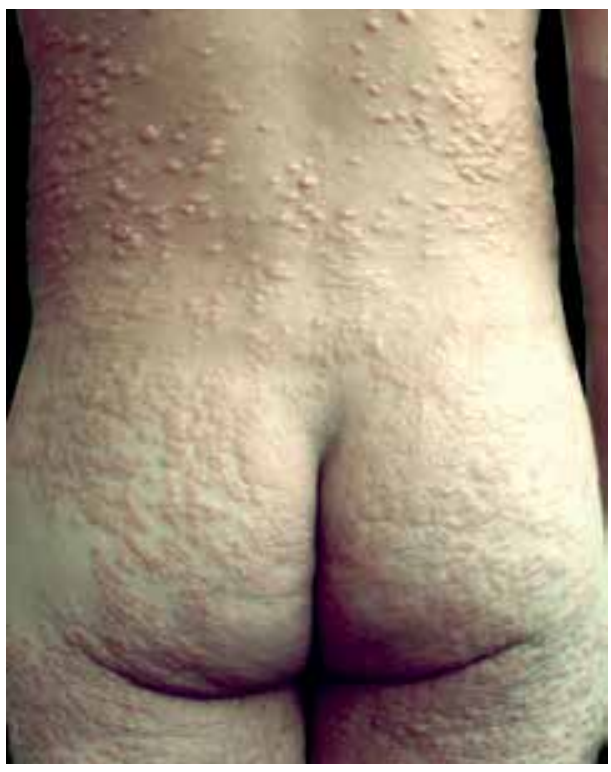

FIGURE 3: Lepromatous leprosy. Infiltration, isolated and confluent, disseminated hansenomas. The patient had cubital claw. Bacilloscopy $6+$

Source: Photo by Dilivros Editora. Talhari S et al., 2015. ${ }^{2}$ seen throughout the course of the disease; they can occur before, during and after treatment. They are due to bacilli destruction and releasing of antigenic particles. In $\mathrm{BL}$, they are a consequence of the abnormal cellular immune-response, known as type I reactions or reverse reactions (RR). The cutaneous lesions acquire a swollen aspect and can become ulcerated; nerve trunks increase in size and become spontaneously painful, particularly to touch. In type II reaction most frequent clinical manifestation is the erythema nodosum leprosum (ENL), it occurs mainly in LL patients and less commonly in BLL patients. It is a systemic inflammatory reaction, mediated by immunocomplexes. There is frequently fever and compromise of the general health. Besides skin and nerves, joints, muscles, tendons, bones, lymph nodes, eyes, testicles, liver, among other organs, can also be affected. ${ }^{31}$

\section{DIAGNOSIS}

The diagnosis of leprosy is, in most cases, clinical-epidemiological, and based mainly on dermatological and neurological examination. Testing for temperature, pain and touch sensation is essential for the clinical diagnosis; however, many lesions of the indeterminate and multibacillary clinical forms can present with normal sensitivity, or actually pain during the reactions.
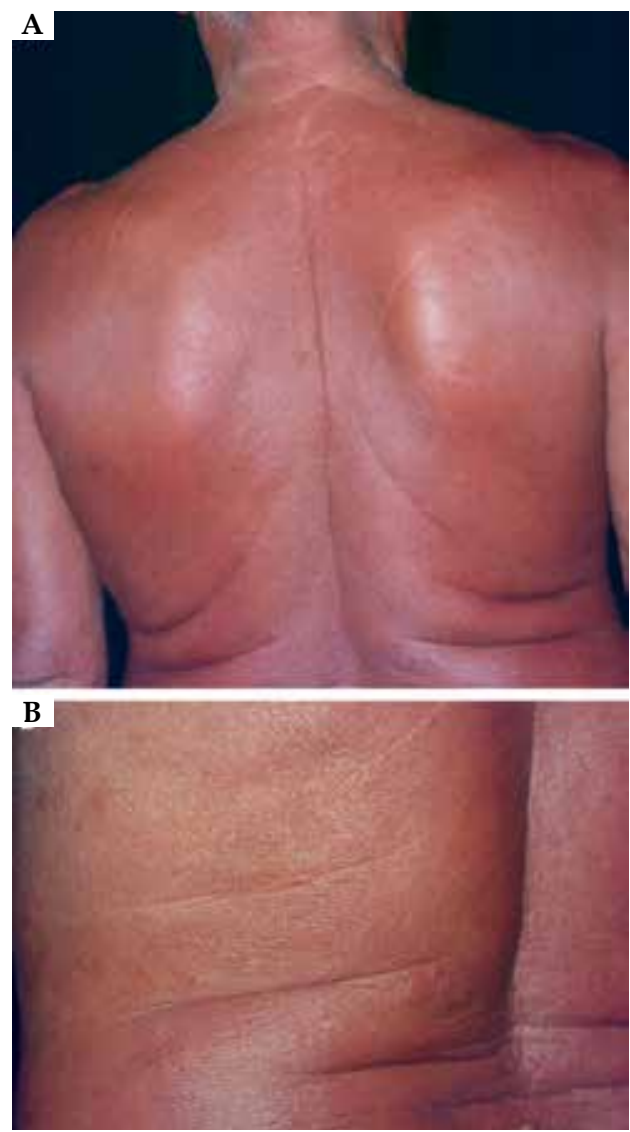

Figure 4: A. Erythema and diffuse infiltration of all skin. Bacilloscopy $6+$. B. Close up of figure 4A. note the micropapular lesions (hansenomas) all over the infiltrated area

Source: Photo by Dilivros Editora. Talhari S et al., 2015.² 

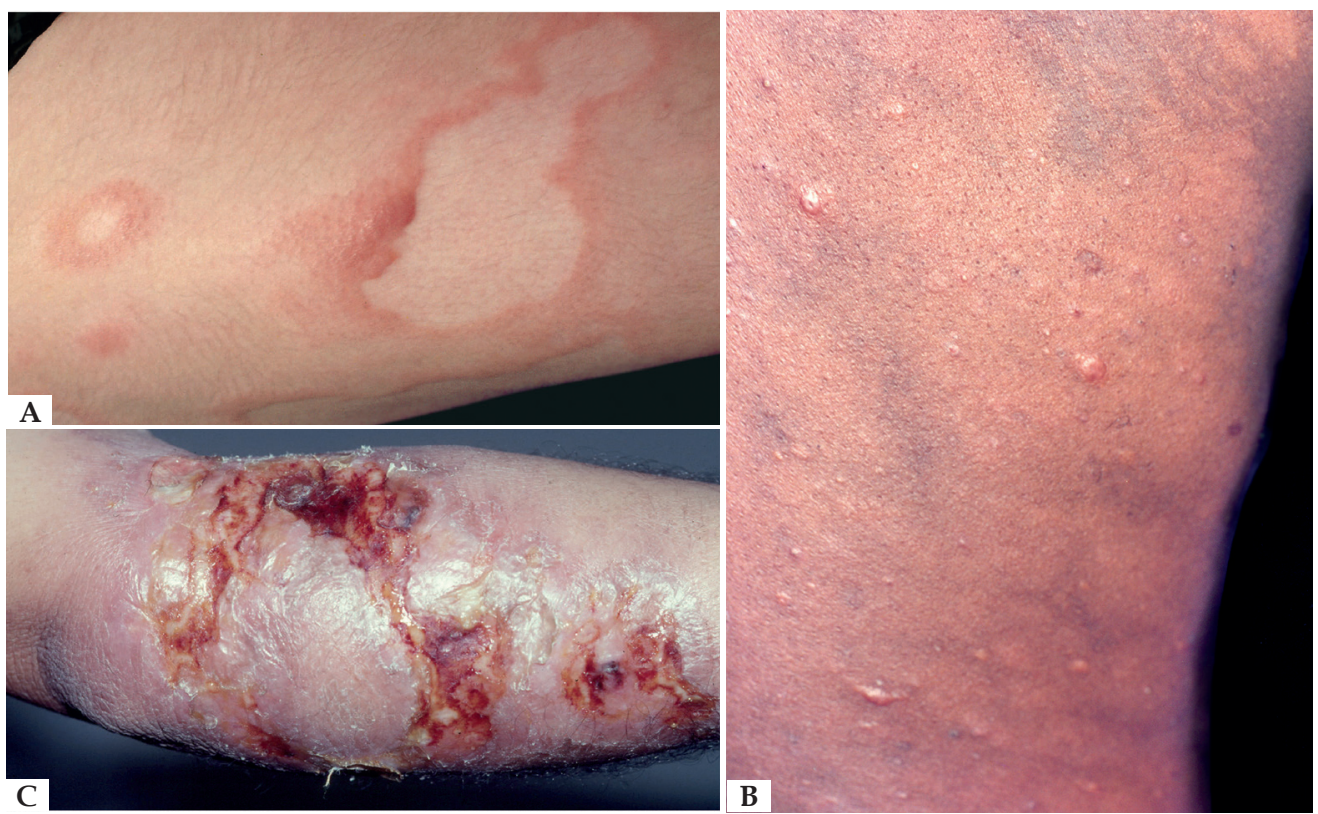

Figure 5: A. BB leprosy. Multiple plaques with apparently spared and well-defined centers. Central areas are hypopigmented, corresponding to IL; peripheral areas are infiltrated, with ill-defined borders. 5B. BL leprosy. Diffuse erythematous infiltration almost all over the skin; hansenomas and areas of normal skin. 5C. Reaction of BT leprosy. This reaction (type I) is often misdiagnosed as Lúcio's phenomenon. Few bacilli on histopathology

Source: Photo by Dilivros Editora. Talhari S et al., 2015.2
Laboratory tests are important and necessary, mainly in the cases mentioned above, in the pure neural form and in the differential diagnosis between reaction and recurrence. Whenever possible, the bacilloscopy must be made, and the following tests should be available: histamine test, pilocarpine test, histopathology, anti-PGL-1 (phenolic glycolipid antigen) serology and the polymerase chain reaction (PCR). Electroneuromyography, ultrasound or magnetic resonance of nerve trunks can be useful in the diagnosis of neural forms. Recent studies have shown that the rapid diagnostic tests, based on the detection of anti-peptide antibodies derived from bacillary PGL, are also important for the diagnosis.

\section{MAIN DRUGS USED FOR LEPROSY TREATMENT}

The treatment of leprosy is an outpatient treatment, using 1982 WHO standardized regimens, which is basically three first-line drugs: dapsone, rifampicin and clofazimine. ${ }^{13}$ This association is known as MDT or polychemotherapy (PCT).

Sulfone (diaminodiphenyl sulfone - DDS), also known as dapsone, has mainly a bacteriostatic action, with low bactericidal activity. ${ }^{33}$ It probably acts as an antagonist of the para-aminobenzoic acid (PABA), preventing its utilization in the synthesis of folic acid by $M$. leprae. It is well-tolerated, with many side effects that, in the majority of cases, do not lead to discontinuation of treatment. ${ }^{34}$

The first therapeutic trial with dapsone was performed by Faget, in 1941, in the United States. ${ }^{33}$ This was the first drug proven to be effective against $M$. leprae. In view of the excellent initial results, dapsone is used in leprosy control programs all over the world. ${ }^{33}$ It was believed that leprosy would be eradicated with this drug. In 1966, WHO recommended that after the bacilloscopy turned negative, the treatment with dapsone should be continued for five more years. ${ }^{35}$ In the different endemic countries, this recommendation was not followed, ranging from longer periods than the recommended, or even throughout life. Among the main side effects, gastritis, headaches, photodermatitis, hemolysis methemoglobinemia, hemolytic anemia, agranulocytosis, hepatitis, dapsone syndrome, peripheral neuropathy and nephrotic syndrome can be included. ${ }^{36-41}$

The first reports of dapsone resistance are from the 1960s experimentally proven by Pettit and $\operatorname{Rees}^{42}$, Pearson et al. ${ }^{43}$, among others. In certain countries, such as Ethiopia, sulfone resistance reached 100 resistant cases in every 1000 patients treated. In Brazil, Talhari et al. ${ }^{44}$ confirmed six cases of secondary sulfone resistance. Santos, Talhari, Viana et al., in another study, demonstrated different levels of resistance to dapsone in 25 patients out of 33 clinically suspicious cases undergoing sulfone monotherapy for 4 to 37 years. ${ }^{45}$ Dapsone resistance can be primary or secondary.

The use of this drug as monotherapy, misclassification of clinical form, irregular use by patients and mainly prescription of low doses, are among the main causes of drug resistance. Use of dapsone in low doses was due to studies on the minimal inhibitory concentration, that indicated smaller daily doses compared to the ones currently used. In 1977, WHO recommended avoidance of dapsone monotherapy and suggested the combination of drugs to treat MB leprosy. ${ }^{46}$

Since 1978, Brazil Ministry of Health (National Sanitary Dermatology Division - DNDS) established that established that MB patients would be would be treated with the combination of dapsone and rifampicin in the first three months, followed by dapsone alone. ${ }^{47}$ In the majority of health care falcilities, dapsone was almost always prescribed indefinitely. Upon suspicios of dapsone resistance, it was replaced by clofazimine..$^{47}$ At that time, the combination of DDS and rifampicin was rejected, since patients with potential dapsone resistance would be undergoing rifampicin as monotherapy and could develop resistance to the latter.

Rifampicin (RMP), a semi synthetic derivative of rifamycin $\mathrm{B}$, has mainly bactericidal action. It acts inhibiting the RNA-polymerase enzyme in the multiplying bacillus. RMP started to be used in leprosy since $1963 .^{48}$ Its use is important in all clinical forms of leprosy and within a few days of treatment, most of the bacilli become unviable. It's believed that the combination of DDS and RMP 
would prevent the appearance of resistance to both drugs. However, in the 1970s, the first cases of rifampicin resistance were identified. ${ }^{49}$ Another important aspect related to RMP and also to DDS is the possibility of finding persistent viable bacilli, even in cases of adequate treatment. A persistent bacillus has an inactive, dormant metabolism, adapted to low concentrations of oxygen; they are mainly found in dermal nerves, smooth muscles, lymph nodes, iris, bone marrow, and liver. Persistent bacilli are found in approximately $10 \%$ of treated MB patients. They could be associated to recurrences or to the development of drug resistance. ${ }^{50}$

Among the described side effects, some of which severe, there are reports of liver toxicity, thrombocytopenia and psychosis. Its intermittent use (monthly doses) can lead to flu-like syndrome. ${ }^{36-41}$ Although not frequent, shock, dyspnea, hemolytic anemia and renal failure can also occur. ${ }^{51,52}$ Face and neck flushing, rash and pruritus, decreased appetite, nausea, vomiting, diarrhea, abdominal pain, malaise, loss of appetite, jaundice, purpura, epistaxis and other manifestations can also be seen. ${ }^{51,52}$ Despite the side effects above mentioned, it is important to note that RMP is well-tolerated by the majority of patients.

The combination DDS/RMP is no longer recommended by WHO since $1981 .{ }^{13}$ From then on, the combination DDS + RMP + clofazimine for multibacillary patients and RMP + DDS for paucibacillary patients is recommended. This combination is known as multidrug therapy (MDT) or polychemotherapy (PCT).

Clofazimine (CLF) is an iminophenazine dye, synthesized by Barry et al. in $1957 .{ }^{53}$ It has a mild bactericidal action, acting slowly on M. leprae and destroying $99 \%$ of the bacteria in approximately five months. Its efficacy is similar to DDS. CLF has an important anti-inflammatory action. In type 2 reactions, it is used as a steroid sparing agent.

In 1962, Browne and Hogerzeil ${ }^{54}$ reported the results of the first patients treated with CLF. In a small series of cases, Barry et al..$^{53}$ in 1957, observed that CLF had similar results to dapsone. In 1964, Shepard and Chang ${ }^{55}$ demonstrated the inhibitory activity of CLF against $M$. leprae in mice feet. In 1965, Browne reported the activity of CLF in the treatment of type II leprosy reactions. ${ }^{56}$ In Brazil, Carvalho-Silva ${ }^{57}$ published the first favorable results of the treatment of leprosy with CLF. Subsequently, Opromolla et al. ${ }^{58}$ and Belda et al..$^{59}$, in 1972, also showed similar results to dapsone. In almost all studies, CLF was used as monotherapy. The pigmentation caused by this drug probably limited its large-scale use. This is one of the explanations for the rare cases of $M$. leprae resistance to this drug. Afterwards, CLF started to be used in large scales, becoming a major component of the multidrug therapy. ${ }^{13}$ Admittedly, this drug, associated to RMP and DDS, would be key for the prevention of drug resistance. This theory was proven along over 30 years of MDT.

The most important side effects of CLF are skin pigmentation, xerosis, hypersensitivity to light, gastrointestinal manifestations and edema of the lower limbs. The pigmentation can be attenuated upon reducing sun exposure. In many cases, after discontinuing the medication, the pigmentation persists for one or more years. ${ }^{36-41}$ In general, the edematous areas of bacillary patients become intensely pigmented because of drug build up. The current smaller than initially recommended CLF dose for MDT, cause less pigmentation. This drug is generally well tolaerated in the currently used regimens.

Among other medications used for leprosy treatment in alternative regimens, the main ones are ofloxacin, minocycline and clarithromycin. ${ }^{60}$

Ofloxacin is an antibiotic in the quinolone group, and is also important for leprosy treatment. It has bactericidal activity, and is used in daily doses of $400 \mathrm{mg}$. After four weeks of treatment, $99.9 \%$ of the bacilli become unviable. This drug should not be given to children under five years of age, pregnant or breast-feeding women. Among other side effects, gastrointestinal manifestations, photodermatitis, cutaneous pigmentation and central nervous system changes, such as insomnia, headaches, dizziness, nervousness, and hallucinations can be observed. ${ }^{60,61}$

Minocycline is the only tetracycline with bacterial action on M. leprae; it is superior to clarithromycin, but substantially inferior to RMP. It is used in the dose of $100 \mathrm{mg} /$ day. Its main side effects are skin, mucous membranes and teeth pigmentation; gastrointestinal and central nervous system abnormalities can also occur. ${ }^{61}$ This drug has been used as an alternative in a small number of cases. ${ }^{61-63}$

Clarithromycin has bactericidal action on M. leprae; it is used in the dose of $500 \mathrm{mg} /$ day. In experimental studies, this macrolide destroyed $99 \%$ of the bacilli in 28 days; and in 55 days, $99.9 \%$ of the bacilli become unviable. ${ }^{64}$ The main side effects are gastrointestinal disturbances, mainly nausea, vomiting and diarrhea. ${ }^{60,61}$

Among other medications with potential to treat leprosy, there are sparfloxacin, that have a similar action to ofloxacin, and moxifloxacin, more potent than ofloxacin, minocycline and clarithromycin. Perfloxacin, rifamycin, rifapentine, diarylquinoline and nitroimidazopyran are drugs that can also be used in alternative regimens. ${ }^{61,64-75}$

\section{Multidrug therapy (MDT) or Polychemotherapy (OMS/1981)}

The drug combination recommended by WHO in 1981 (multidrug therapy or polychemotherapy - MDT or PCT) represents an important mark on leprosy treatment. Dapsone, rifampicin and clofazimine are combined. This therapeutic regimen is effective for the treatment and the prevention of drug resistance; it made possible to cure thousands of patients, including patients with resistance to the components of MDT. ${ }^{76-79}$

For the paucibacillary adults, its recommended: dapsone $100 \mathrm{mg} /$ day, and rifampicin - $600 \mathrm{mg}$, once a month in supervised doses for six months. For the multibacillary, clofazimine - $100 \mathrm{mg} /$ day' $^{\prime}+300 \mathrm{mg} /$ month was added to the PB regimen, with 24 months duration or until the bacilloscopy is negative. ${ }^{13}$ For adults that weigh less than $35 \mathrm{~kg}$, the doses are adjusted, rifampicin being $450 \mathrm{mg} /$ month and the dapsone $50 \mathrm{mg}$ ( 1 to $2 \mathrm{mg} / \mathrm{kg}$ /weight/day). The dose of clofazimine is variable, 50 to $100 \mathrm{mg} /$ day. For children, the same regimens, in the following doses: up to five years of age, dapsone $25 \mathrm{mg}$ / day, rifampicin 150 to $300 \mathrm{mg} /$ month, clofazimine 100 $\mathrm{mg} / \mathrm{month}$ and $100 \mathrm{mg} /$ week; from 6 to 14 years of age, dapsone 50 to $100 \mathrm{mg}$ / day, rifampicin, 300 to $450 \mathrm{mg} /$ month and clofazimine, $150 \mathrm{mg} /$ week and 150 to $200 \mathrm{mg} / \mathrm{month} \cdot$. $^{13,80,81}$

In the first few years when MDT was implemented, the majority of multibacillary patients was treated until bacilloscopy 
became negative. In 1994, WHO recommended a fixed duration treatment for $\mathrm{MB}$ patients, with 24 doses, regardless of negative bacilloscopy, because after this treatment leght, the bacilli found were not viable, and were progressively eliminated in alogarithmic rate of $0.66 /$ year of its initial bacillary load, this theory was confirmed a few years after this decision was made..$^{29,60}$

During this period, some articles demonstrated that the combination of a single dose of rifampicin $-600 \mathrm{mg}$, minocycline $100 \mathrm{mg}$ and ofloxacin $-400 \mathrm{mg}$, provided cure for a high percentage of patients with a single cutaneous lesion. This regimen, known as ROM, showed efficacy of over $80 \%$ in a study of series of cases; it was not implemented in the majority of the endemic countries. ${ }^{82-84}$

In 1998, WHO recommended the reduction of MDT for multibacillary patients for 12 months.${ }^{30}$ For PB the treatment remained the same six months regimen. In some studies, it was observed that the efficacy of 12 doses was similar to the 24-month regimen. . $^{85,86}$ Therefore, since the initial 1981 recommendation for MDT, the treatment has been modified regarding its length: initially, it was done until bacilloscopy became negative; afterwards, 24 doses; and, currently, 12 months. The efficacy has been similar, regardless of the duration of therapy. $13,29,30,87$

\section{UNIFORM (U-MDT) FOR PB AND MB PATIENTS, WITH NO NEED FOR CLINICAL OR LABORATORY CLASSIFICATION FOR TREATMENT PURPOSES}

Despite the success of MDT, the complexity to operate this regimen across all health systems, the prolonged treatment time, and difficulty in patient compliance, reinforce the need of regimens that are shorter and easier to implement in primary health care system. ${ }^{88-90}$ In 2002, WHO's Technical Advisory Committee meeting, discussed the simplification and treatment length reduction. It was also suggested that the classification of patients into clinical forms for treatment purposes wasn't necessary. Studies development to investigate the feasibility of a Uniform Multidrug Therapy (U-MDT) regimen for PB and MB patients, with a fixed duration of six months, was recommended at this meeting. ${ }^{88}$

From that recommendation, Kroger et al., ${ }^{91}$ 2008, in India and China, developed an open cohort studies, without control groups, from 2003 to 2007, aiming to evaluate the efficacy of U-MDT. In total, 2,912 patients participated in the study and classification was based on the number of skin lesions; 1,777 PBs and 1,135 MBs. ${ }^{91}$ All patients received the same therapeutic regimen: rifampicin and clofazimine in monthly doses and clofazimine and dapsone daily for six months. The conclusion was that U-MDT clinically improved skin lesions, was effective for PB and MB and that it would be possible to implement in health services. The authors considered the results in MB patients promising, however, the follow-up data predicted for 2013 still haven't been published.

Another controlled clinical study was conducted in India, from 2003 to 2005, comparing the efficacy of U-MDT and MDT/WHO for $\mathrm{PB}$ and $\mathrm{MB}$ patients. ${ }^{86}$ At the end of the study, 64 patients were assessed: 32 PB (18 in the U-MDT group and 14 in the control group) and $32 \mathrm{MB}$ (10 in the U-MDT group and 22 in the control group). The follow-up ranged from 18 to 24 months. The authors concluded, with this short follow-up time, that U-MDT was effective and useful to treat $\mathrm{PB}$ patients. However, it was observed that for MB patients, this regimen is not as effective as MDT/WHO with 12 months duration.

The preliminary results of a clinical trial performed in China with $144 \mathrm{MB}$ patients, and maximum follow-up of six years, demonstrated one recurrence thirteen months after discharge. The authors concluded that the uniform regimen induces a rapid drop in bacilli activity, permanent drop in BI, low recurrence rate and an acceptable frequency of reactions. ${ }^{92}$ After eight years of follow-up, there were no efficacy changes. ${ }^{93}$

Rfrom a study conducted in Bangladesh, comparing two similar cohorts - U-MDT-MB and WHO-MDT-MB were recently published. The authors concluded that the treatment length reduction for MB patients, from 12 to six months did not increase the recurrence rates..$^{94}$

Under the denomination "Independent Brazilian study for the assessment of efficacy of the uniform multidrug therapy regimen in the treatment of patients with leprosy (U-MDT/CT-BR)", a clinical trial with prolonged follow-up was developed. The investigation was undertaken in two leprosy National Reference Centers: Fortaleza (CDERM), and Manaus (FUAM). To this date, this is the only randomized, controlled clinical trial. Four groups of patients were included, being two of them experimental - U-MDT/PB and U-MDT/MB and two control groups - R-MDT/PB and R-MDT/ MB. ${ }^{95}$ This clinical trial was financed by DECIT/CNPq and registered in the International Clinical Trials Registry of the National Institute of Health (ClinicalTrials.gov). The recruitment for the U-MDT clinical trial above-mentioned started in March 2007. Overall, 858 patients fulfilled the study inclusion criteria, accepted participating and were recruited..$^{95}$

The partial results of U-MDT/CT-BR in 2012 demonstrated that there was no statistically significant difference in the frequency of reactions between the treatment groups. It was also seen that the frequency of the first reaction occurrence, after two years of the beginning of treatment, was not statistically different between the group that received R-MDT and those who received U-MDT. No specific type of reaction was associated to treatment duration. ${ }^{96}$

Analysis of reactions frequency among MB patients wasn't markedly different between the groups that received regular twelve or six months treatment (Graph 2) ${ }^{96}$ There was no statistically significant difference when the four groups were compared, $U$ and R-MDT, with BI lower and higher than three (Graph 3). The analysis of BI reduction was also performed through the estimation of MI mean reduction as a function of time and not as the mean reduction of BI for all patients as in the traditional regression analyses, that tend to over estimate results. This analysis showed a higher reduction in BI of patients treated with the regular regimen; however, this reduction was not significantly higher than the one from patients treated with U-MDT (Graphs 4 and 5). ${ }^{97}$

A descriptive epidemiological study based on U-MDT/CTBR to verify PB patient satisfaction regarding the use of clofazimine, identified that $6.9 \%(15 / 217)$ manifested the desire to discontinue the medication due to changes in skin color. These results showed that the introduction of clofazimine in the treatment of PB patients did not negatively impact patient satisfaction. ${ }^{98}$ The final results of the study were recently submitted for publication. 
The introduction of MDT in 1981 was responsible for important developments in leprosy control programs. ${ }^{13}$ However, the three drugs combination as a therapeutical regimen is not ideal: it has only one bactericidal agent,treatment lenght is long, cutaneous pigmentation can be marked and there can be other adverse effects. These reasons point towards the need for new studies, with new therapeutical regimens. ${ }^{99}$ However, the disease complexity, methodological difficulties for clinical trials development and the difficulty in reproducing the in vitro findings in clinical practice are some of the obstacles.

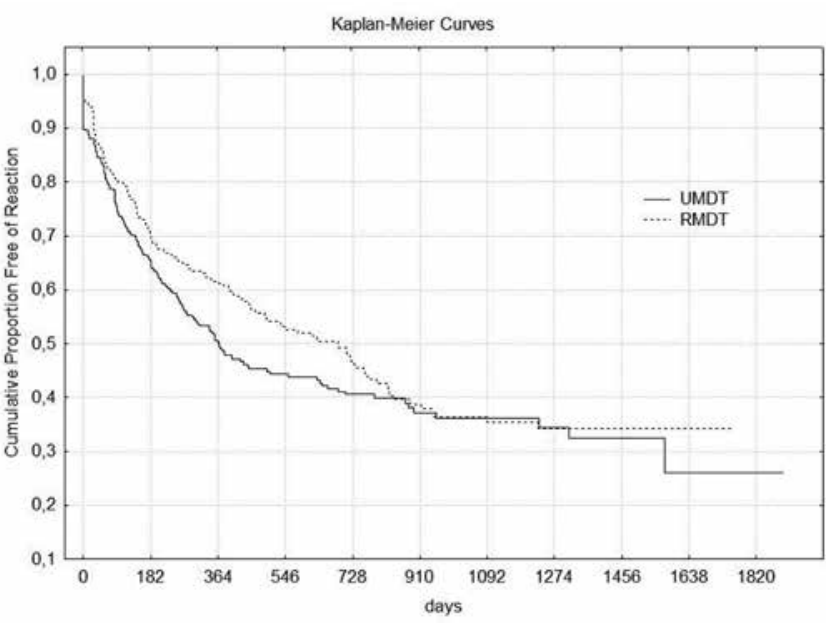

GraPH 2: Kaplan-Meier curve comparing reactions between U-MDT and R-MDT

Source: Penna ML et al., 2012. ${ }^{103}$

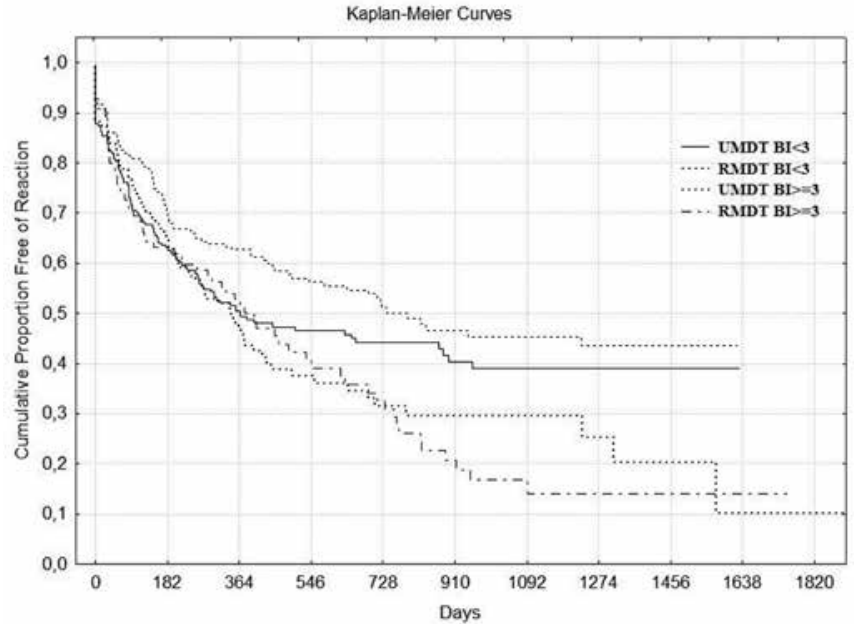

GraPH 3: Kaplan-Meier curve, comparing U-MDTBI<3, R-MDT$\mathrm{BI}<3, \mathrm{U}-\mathrm{MDT}=$ or $>3$ and $\mathrm{R}-\mathrm{MDT}=$ or $>3$

Source: Penna ML et al., 2012.96
New highly bactericidal antibiotics and immunomodulating drugs would be potential candidates to improve compliance and patients quality of life. The ideal therapeutic regimen would be a short course of a new combination of drugs, simple and accessible to the majority of patients. ${ }^{99,100}$ However, there is nothing in short or medium period of time to replace MDT. ${ }^{101}$ Therefore, while this is the recommended regimen, it must be made accessible to the greatest possible number of patients. Current data indicate that U-MDT makes it possible to simplify diagnosis and treatment, reducing duration of the therapeutic course to six months.

Recently, among central strategies for leprosy control in the quadrennium 2017/2020, WHO recommended the implementation of U-MDT. ${ }^{102-103}$
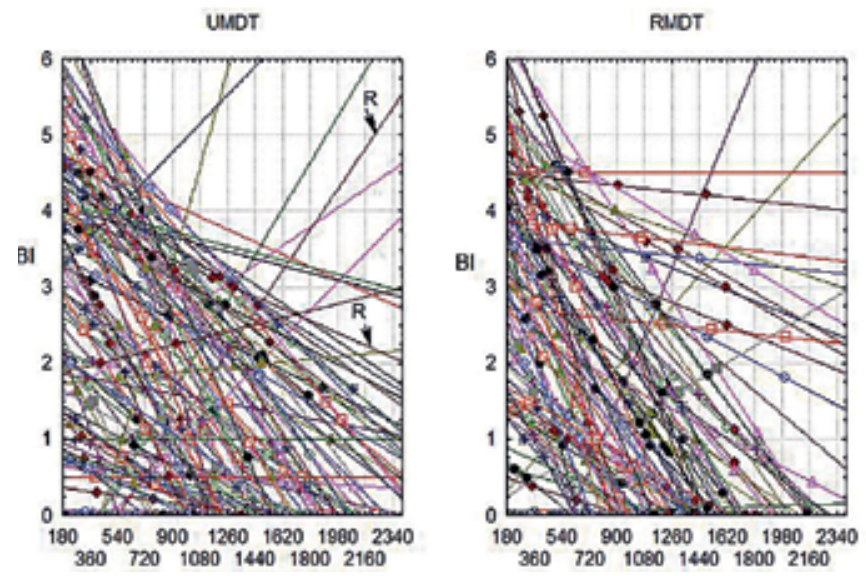

GRAPH 4: Individual regression of the bacilloscopic index (BI) of the patients of the two study groups, 180 days after starting the treatment. $\mathrm{R}=$ Recurrence

Source: Penna GO et al., 2017.103

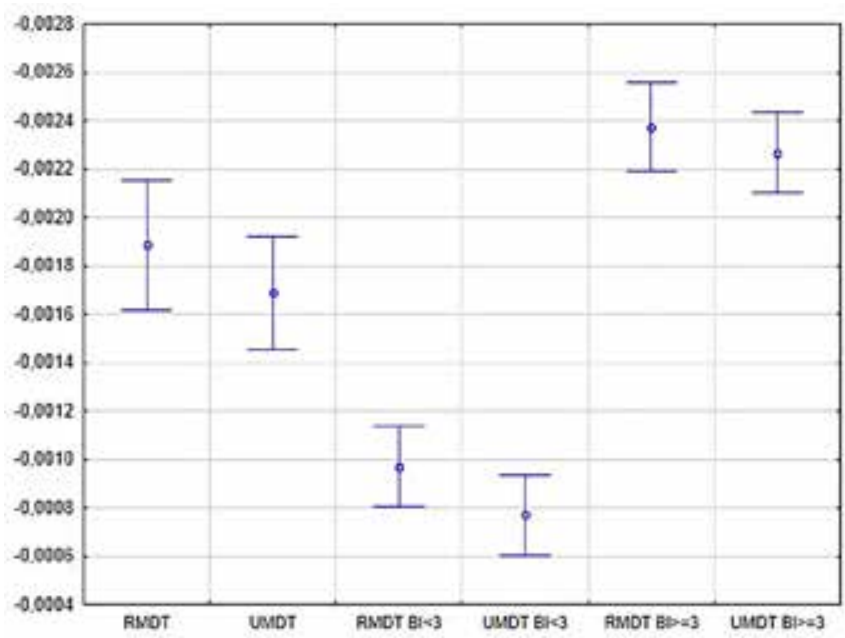

GraPH 5: 95\% confidence interval of the BI reduction, per day, for the patients treated with U-MDT and R-MDT, after 180 days. All patients were stratified according to the BI

Source: Penna GO et al., 2017.103 


\section{REFERENCES}

1. Pfaltzagraff RE, Bryceson A. Clinical Leprosy. In: Bryceson A, Pfaltzgraff RE. Leprosy. 2. ed. Churchill Livingstone: New York and Edinburg; 1979. p.15-30.

2. Talhari S, Penna GO, Gonçalves HS, Oliveira MLW. Aspectos Gerais da Hanseníase, Agente Etiológico, Transmissão, Patogenia, Classificação, Manifestação Clínica, Diagnóstico. In: Talhari S, Penna GO, Gonçalves HS, Oliveira MLW. Hanseníase. 5. ed. Di Livros: Rio de Janeiro; 2015. p.1-94-172.

3. Han XY, Seo YH, Sizer KC, Schoberle T, May GS, Spencer JS, et al. A New Mycobacterium Species Causing Diffuse Lepromatous Leprosy. Am J Clin Pathol. 2008;130:856-64.

4. Han XY, Silva FJ. On the Age of Leprosy. PLoS Negl Trop Dis. 2014;8:e2544.

5. Fine PE. Leprosy: the epidemiology of a slow bacterium. Epidemiol Rev. 1982:4:161-88.

6. Leininger JR, Donham KJ, Rubino MJ. Leprosy in a Chimpanzee: Morphology of the skin lesions and characterization of the organism. Vet Pathol. 1978;15:339-46.

7. Walsh GP, Meyers WM, Binford CH, Gerone PJ, Wolf RH, Leininger JR. Leprosy a zoonosis. Lepr Rev. 1981;52:77-83.

8. Moet FJ, Meima A, Oskam L, Richardus JH. Risk factors for the development of clinical leprosy among contacts, and their relevance for targeted interventions. Lepr Rev. 2004;75:310-26.

9. Truman RW, Singh P, Sharma R, Busso P, Rougemont J, Paniz-Mondolfi A, et al. Probable Zoonotic Leprosy in the Southern United States. N Engl J Med. 2011;364:1626-33.

10. Kerr-Pontes LR, Barreto ML, Evangelista CM, Rodrigues LC, Heukelbach J, Feldmeier H. Socioeconomic, environmental, and behavioral risk factors for leprosy in North-east Brazil: Results of a case-control study. Int J Epidemiol. 2006;35:994-1000.

11. World Health Organization. WHO Expert Committee on Leprosy. World Health Organization, Tech Rep Series. 2012;1-61

12. Aguas JT. La lepra: pasado, presente y futuro. In: Bacteriologia. Valencia: Ed Valenciana; 1999. p.77-88.

13. Chemotherapy of leprosy for control programmes: report of a WHO study group. Technical Report Series, 675. WHO: Geneva; 1982.

14. Weekly epidemiological record. Relevé Épidémiologique Hebdomadaire. WHO, 88th year. 2013;32:337-348

15. World Health Organization leprosy elimination project: status report 2002. WHO: Geneva; 2003

16. World Health Assembly. Forty-fourth World Health Assembly, Geneva, 6-16 May 1991: resolutions and decisions, annexes. Geneva: World Health Organization; 1991.

17. Bobin P. Peut- on programmer l'éradication, l'élimination ou le contrôle d'une maladie infectieuse? L'exemple de la lèpre. Bull l' ALLF. 2005;16:3-8.

18. Rodrigues LC, Lockwood DJ. Leprosy now: epidemiology, progress, challenges, and research gaps. Lancet Infect Dis. 2011;11:464-70.

19. Fine PE. Reflections on the elimination of leprosy. Int J Lepr Other Mycobact Dis. 1992;60:71-80.

20. Penna ML, Temporão JG, Grossi MA, Penna GO. Leprosy control: knowledge shall not be neglected. J Epidemiol Community Health. 2011;65:473-4.

21. Scollard DM. Leprosy research declines, but most of the basic questions remain unanswered. Int J Lepr Other Mycobact Dis. 2005;73:25-7.

22. Lockwood DN, Shetty V, Penna GO. Hazards of setting targets to eliminate disease: lessons from the leprosy elimination campaign. BMJ. 2014;348:g1136.

23. Penna ML, Penna GO. Trend of case detection and leprosy elimination in Brazil. Trop Med Int Health. 2007;12:647-50.

24. Penna ML, de Oliveira ML, Penna GO. The epidemiological behavior of leprosy in Brazil. Lepr Rev. 2009;80:332-44.

25. Rabello FE, Fraga S. Hanseníase: definição, conceituação e sintomatologia geral. In: Rabello FE, Fraga S. Atlas de Dermatologia: Fundamentod de Medicina Cutânea. Guanabara: Rio de Janeiro; 1970. p.166-177.

26. Bechelli LM, Curban GV. Classificação da lepra. 6. Congresso Internacional de Leprologia. Madrid, 1953. In: Bechelli LM, Curban GV. Compendio de Dermatologia. São Paulo: Atheneu; 1975. p. 124-125.

27. Ridley DS, Jopling WH. Classification of leprosy according to immunity. A fivegroup system. Int J Lepr Other Mycobact Dis. 1966;34:255-73.

28. WHO Expert Committee on Leprosy. Technical Report Series, 768, Sixth Report. WHO: Geneva; 1988.

29. World Health Organization. Enhanced global strategy for further reduce the disease burden due to leprosy (plan period 2011-2015). Regional Office for South-East Asia, New Delhi, 2009.

30. World Health Assembly (WHA). Resolutions on Neglected Tropical Diseases: 1948-2013. Geneva: World Health Organization; 2013.

31. Naafs B. Leprosy reactions. New knowledge. Trop Geogr Med. 1994;46:80-4.
32. Modlin RL, Melancon-Kaplan J, Young SM, Pirmez C, Kino H, Convit J, et al. Learning from lesions: patterns of tissue inflamation in leprosy. Proc Natl Acad Sci U S A. 1988:85:1213-7.

33. Faget GH, Pogge RC, Johansen FA, Dinan JF, Prejean BM, Eccles CG. The promin treatment of leprosy. A progress report. Int J Lepr Other Mycobact Dis. 1966;34:298-310.

34. Penna GO, Talhari S, Pontes MAA, Oliveira MLW, Gonçalves HS. Tratamento da hanseníase. In: Talhari S, Penna GO, Gonçalves HS, Oliveira MLW. Hanseníase. 5. ed., Rio de Janeiro, DiLivros; 2015; p. 173-185.

35. WHO Expert Commitee on Leprosy. Geneva, 27 July to 2 August 1965, Third Report, 1966.

36. Gallo MEN, Nery JAC, Garcia CC. Intercorrências pelas drogas utilizadas nos esquemas poliquimioterápicos em hanseníase. Hansen Int. 1995;20:46-50.

37. Brasil MT, Opromolla DV, Marzliak ML, Nogueira W.. Results of a surveillance system for adverse effects in leprosy's WHO/MDT. Int J Lepr Other Mycobact Dis. 1996;64:97-104.

38. Cunha Mda G, Schettini AP, Pereira ES, Pedrosa VL, Cruz RC, Sadahiro M, et al. Adverse Effects in Leprosy's WHO/MDT and paramedic's role in leprosy control program Regarding Brasil. Int J Lepr Other Mycobact Dis. 1997;65:257-9.

39. Deps PD, Nasser S, Guerra P, Simon M, Birshner Rde C, Rodrigues LC. Adverse effects from multi-drug therapy in leprosy: a Brazilian study. Lepr Rev. 2007;78:216-22.

40. Rao PN, Lakshmi TS. Increase in the incidence of dapsone hypersensitivity syndrome--an appraisal. Lepr Rev. 2001;72:57-62.

41. Dupnik KM, Cardoso FJ, De Macêdo AL, De Sousa IL, Leite RC, Jerônimo SM, et al. Intolerance to leprosy multi-drug therapy: more common in women? Lepr Rev. 2013;84:209-18.

42. Pettit JH, Rees RJ. Sulphone resistance in leprosy. an experimental and clinical study. Lancet. 1964;2:673-4.

43. Pearson JMH. The Problem of Dapsone-Resistant Leprosy. Int J Lepr Other Mycobact Dis. 1981;49:417-20.

44. Talhari S, Damasco MHS, Souza Cunha MG, Schettini AP, Andrade LMC. Sulfonoresistência: comprovação laboratosial em seis casos. An Bras Dermatol. 1985;60:175-8.

45. Damasco MHS, Talhari S, Viana SM, Signorelli M, Saad MH, Andrade LM. Secondary dapsone-resistant leprosy in Brazil: a preliminary report. Lepr Rev. 1986;57:5-8.

46. WHO Expert Committee on Leprosy: fifth report. Technical Report Series 607 . World Health Organization: Geneva; 1977.

47. Brasil. Ministério da Saúde. Portaria n. 165, de 14 de maio de 1976. Estabelece política de controle da hanseníase. Diário Oficial União. 11 jun 1976.

48. Opromolla D V. Primeiros resutados com a "Rifampicina SV" na lepra lepromatosa. In: Anais do 8. Congresso Internacional de Leprologia, Rio de Janeiro, 1963. Rio de Janeiro: Serviço Nacional de Lepra; 1963. p. 346-55.

49. Jacobson RR, Hastings RC. Rifampin-resistant leprosy. Lancet. 1976;2:1304-5.

50. Ramu G. Clinical features and diagnosis of relapses in leprosy. Indian J Lepr. 1995:67:45-59.

51. Souza CS, Alberto FL, Foss NT. Disseminated intravascular coagulopathy as an adverse reaction to intermittent rifampin schedule in the treatment of leprosy. Int $J$ Lepr Other Mycobact Dis. 1997;65:366-71.

52. Opromolla DVA. As reações adversas à rifampicina com especial referência à insuficiência renal aguda. Hansenol Int. 1992;17:1-4.

53. Barry VC, Belton JG, Conalty ML, Denneny JM, Edward DW, O'sullivan JF, et al. A new series of phenazines (rimino-compounds) with high antituberculosis activity. Nature. 1957;179:1013-5.

54. Browne SG, Hogerzeil LM. "B 663" in the treatment of leprosy. Preliminary report of a pilot trial. Lepr Rev. 1962;33:6-10.

55. Shepard CC, Chang YT. Activity of antituberculosis drugs against mycobacterium leprae. Int J Lepr. 1964;32:260-71.

56. Browne SG, Harman DJ, Waudby H, McDougall AC. Clofazimine (Lamprene, B663) in the treatment of lepromatous leprosy in the United Kingdom. A 12 year review of 31 cases, 1966-1978. Int J Lepr Other Mycobact Dis. 1981;49:167-76.

57. Silva NC, Zeo A, Azulay RD, Portelo AB. Terapeutica da lepra pela clofazimina. An Bras Dermatol. 1972;47:1-6.

58. Opromolla DVA, Dalpino D, Tonello CJS, Fleury RN, Neto J. Resultados iniciais com clofazimina no tratamento da hanseníase. An Bras Dermatol. 1972;47:15-17.

59. Belda W. Experimentação clínica com a clofazimina no tratamento ambulatorial da hanseníase. An Bras Dermatol. 1972;47:19-37.

60. WHO study Group on Chemotherapy. Chemotherapy of Leprosy: Report of a Study Group. WHO Technical Report Series, 847. Geneva; 1994.

61. 61. Ji B, Perani EG, Grosset JH. Effectiveness of clarithromycin and minocycline alone and in combination against experimental Mycobacterium leprae infection in mice. Antimicrob Agents Chemother. 1991;35:579-81. 
62. Gelber RH. Activity of minocycline in Mycobacterium leprae-infected mice. J Infect Dis. 1987;156:236-9.

63. Gelber RH, Fukuda K, Byrd S, Murray LP, Siu P, Tsang M, et al. A clinical trial of minocycline in lepromatous leprosy. BMJ. 1992;304:91-2.

64. Ji B, Perani EG, Petinom C, N'Deli L, Grosset JH. Clinical trial of ofloxacin alone and in combination with dapsone plus clofazimine for treatment of lepromatous leprosy. Antimicrob Agents Chemother .1994;38:662-7.

65. Franzblau SG, White KE. Comparative in vitro activities of 20 fluoroquinolones against Mycobacterium leprae. Antimicrob Agents Chemother. 1990;34:229-31.

66. Guelpa-Lauras CC, Perani EG, Giroir AM, Grosset JH. Activities of pefloxacin and ciprofloxacin against Mycobacterium leprae in the mouse. Int $\mathrm{J}$ Lepr Other Mycobact Dis. 1987;55:70-7.

67. Traore I, Ji B, Lienhardt C, Bobin P, Grosset J. Determination of the minimal effective dosages of ofloxacin and sparfloxacin against M. leprae in the mouse foot pad system. Int J Lepr Other Mycobact Dis. 1996;64:142-5.

68. Pattyn SR. Activity of ofloxacin and pefloxacin against Mycobacterium leprae in mice. Antimicrob Agents Chemother. 1987;31:671-2.

69. Chan GP, Garcia-Ignacio BY, Chavez VE, Livelo JB, Jimenez CL, Parrilla ML, et al. Clinical trial of sparfloxacin for lepromatous leprosy. Antimicrob Agents Chemother. 1994:38:61-5.

70. Pardillo FE, Burgos J, Fajardo TT, Dela Cruz E, Abalos RM, Paredes RM, et al Powerful bactericidal activity of moxifloxacin in human leprosy. Antimicrob Agents Chemother. 2008;52:3113-7.

71. Consigny S, Bentoucha A, Bonnafous P, Grosset J, Ji B. Bactericidal Activities of HMR 3647, Moxifloxacin, and Rifapentine against Mycobacterium leprae in Mice. Antimicrob Agents Chemother. 2000;44:2919-21.

72. Pattyn SR, Saerens EJ. Activity of three new rifamycin derivatives on the experimental infection by Mycobacterium leprae. Ann Soc Belg Med Trop. 1977; $57: 169-73$

73. Andries K, Verhasselt P, Guillemont J, Göhlmann HW, Neefs JM, Winkler H, et al A diarylquinoline drug active on the ATP synthase of Mycobacterium tuberculosis. Science. 2005;307:223-7.

74. Diacon AH, Pym A, Grobusch M, Patientia R, Rustomjee R, Page-Shipp L, et al. The Diarylquinoline TMC207 for Multidrug-Resistant Tuberculosis. N Engl J Med. 2009;360:2397-405.

75. Tyagi S, Nuermberger E, Yoshimatsu T, Williams K, Rosenthal I, Lounis N, et al. Bactericidal activity of the nitroimidazopyran PA-824 in a murine model of tuberculosis. Antimicrob Agents Chemother. 2005:49:2289-93.

76. Erickson PT. Relapse following apparent arrest of leprosy by sulfone therapy. Public Health Rep. 1950:65:1147-57.

77. Lowe J. The late results of sulphone treatment of leprosy in East Nigeria. Lepr Rev. 1954:25:113-24.

78. Rodriguez $\mathrm{JN}$. Relapses after sulfone therapy in leprosy of the lepromatous type. Int J Lepr. 1959;26:305-12.

79. Quagliato R, Berquó E, Leser WSP. Lepromatoses em tratamento sulfônico. Rev Bras Leprol. 1961; 29: 19-30.

80. World Health Organization. A guide to leprosy control, 2nd ed. Geneva: World Health Organization; 1998.

81. Brasil. Ministério da Saúde. Secretaria de Políticas de Saúde. Departamento de Atenção Básica. Área Técnica de Dermatologia Sanitária. Guia para o controle de hanseníase. Brasilia: Ministério da Saúde; 2002.

82. Shortening duration of treatment of multibacillary leprosy. Action Programme for the Elimination of Leprosy, WHO. Indian J Lepr. 1997;69:267-70.

83. Martelli CM, Stefani MM, Gomes MK, Rebello PF, Peninni S, Narahashi K, et al. Single lesion paucibacillary leprosy: baseline profile of the Brazilian Multicenter Cohort Study. Int J Lepr Other Mycobact Dis. 2000;68:247-57.

84. Gupte MD. Field trials of a single dose of the combination rifampicin-ofloxacinminocycline (ROM) for the treatment of paucibacillary leprosy. Lepr Rev. 2000;71:S77-80.

85. Dogra S, Kumaran MS, Narang T, Radotra BD, Kumar B. Clinical characteristics and outcome in multibacillary (MB) leprosy patients treated with 12 months WHO MDT-MBR: a retrospective analysis of 730 patients from a leprosy clinic at a tertiary care hospital of Northern India. Lepr Rev. 2013;84:65-75.

86. Rao PN, Suneetha S, Pratap DV. Comparative study of uniform-MDT and WHO MDT in Pauci and Multi bacillary leprosy patients over 24 months of observation. Lepr Rev. 2009;80:143-55

87. WHO Expert Committee on Leprosy: seventh report. WHO technical report series, $874 ; 1998$
88. WHO Leprosy Elimination Project: Status Report 2002. WHO/CDS/CPE/CEE, 2003.

89. Cellona RV, Balagon MF, dela Cruz EC, Burgos JA, Abalos RM, Walsh GP, et al. Long-term efficacy of 2 year WHO multiple drug therapy (MDT) in multibacillary (MB) leprosy patients. Int J Lepr Other Mycobact Dis. 2003;71:308-19.

90. Penna GO. Leprosy: the need to employ evidence-based medicine in control policies around the world. Lepr Rev. 2011;82:210-2.

91. Kroger A, Pannikar V, Htoon MT, Jamesh A, Katoch K, Krishnamurthy P, et al. International open trial of uniform multi-drug therapy regimen for 6 months for all types of leprosy patients: Rationale, design and preliminary results. Trop Med Int Health. 2008;13:594-602.

92. Shen J, Yan L, Yu M, Li J, Yu X, Zhang G. Six years follow-up of multibacillary leprosy patients treated with uniform multi-drug therapy in China. Int J Dermatol. 2015:54:315-8

93. Yan L, Shen J, Yu M, Zhang G, Li J, Yu X. Result of eight years follow up among multibacillary patients treated with Uniform Multidrug Therapy in China. Lepr Rev. 2016;87:314-21.

94. Butlin CR, Pahan D, Maug AkJ, Withington S, Nicholls P, Alam K, et al. Outcome of 6 months MB-MDT in MB patients in Bangladesh - Preliminary results. Lepr Rev. 2016;87:171-82.

95. Penna GO, Pontes MA, Cruz R, Gonçalves Hde S, Penna ML, Bührer-Sékula S. Clinical trial for uniform multidrug therapy for leprosy patients in Brazil: Rationale and design. Mem Inst Oswaldo Cruz. 2012;107:22-7.

96. Penna ML, Buhrer-Sékula S, Pontes MA, Cruz R, Gonçalves Hde S, Penna GO. Primary results of clinical trial for uniform multidrug therapy for leprosy patients in Brazil (U-MDT/CT-BR): reactions frequency in multibacillary patients. Lepr Rev. 2012;83:308-19.

97. Penna ML, Bührer-Sékula S, Pontes MA, Cruz R, Gonçalves Hde S, Penna GO Results from the clinical trial of uniform multidrug therapy for leprosy patients in Brazil (U-MDT/CT-BR): decrease in bacteriological index. Lepr Rev. 2014;85:262-6.

98. Ferreira IP, Buhrer-Sékula S, De Oliveira MR, Gonçalves Hde S, Pontes MA, Penna $M L$, et al. Patients profile and treatment satisfaction of Brazilian leprosy patients in a clinical trial of uniform six-month multidrug therapy (U-MDT/CT-BR). Lepr Rev. 2014:85:267-74.

99. Gelber RH, Grosset J. The chemotherapy of leprosy: An interpretive history. Lepr Rev. 2012;83:221-40.

100. Ximena I, Oliveira MLWR, Sales AM, Nery JAC; Sarno E. Considerations on clinical trials of leprosy treatment: need of novel drug combinations. Clin Invest. 2013;3:617-35

101. Ponder E, Moree M. Developing new drugs \& vaccines for neglected diseases of the poor. BIO Ventures for Global Health, 2012.

102. Global Leprosy Strategy 2016 - 2020: Accelerating Towards a Leprosy-Free World. World Health Organization, Regional Office for South-East Asia, WHO; 2016.

103. Penna GO, Bührer-Sékula S, Kerr LRS, Stefani MMA, Rodrigues LC, de Araújo MG, et al. Uniform Multidrug Therapy for leprosy patients in Brazil (U-MDT/CT-BR): Final results of open label, randomized and controlled clinical trial, among MB patients. PLoS Negl Trop Dis. 2017;11:e0005725.

\author{
MAILING ADDRESS: \\ Rossilene Conceição da Silva Cruz \\ R. Codajás, 24 \\ Cachoeirinha \\ 69065-130 Manaus, AM - Brazil \\ Brazil \\ E-mail: rossilenecruz@uol.com.br
}

How to cite this article: Cruz RCS, Bührer-Sékula S, Penna MLF, Penna GO, Talhari S. Leprosy: current situation, clinical and laboratory aspects, treatment history and perspective of the uniform multidrug therapy for all patients. An Bras Dermatol. 2017;92(6):761-73. 


\section{QUESTIONS}

\section{Select the correct option:}

a) Leprosy is a chronic infectious, contagious disease; the infectious agent is Mycobacterium leprae, is an obligate intracellular bacillus that affects skin, nerves, and mucous membranes;

b) The incubation period is of 2- to 5- years for paucibacillary patients and 5- to 10- years for multibacillary patients;

c) Although there is evidence of the presence of M. leprae in skin lesions, breast milk, environment and animals, the main transmission route of $M$. leprae is the respiratory tract, being humans the main natural reservoir of the bacillus. Multibacillary patients are considered the main source of infection in the transmission cycle;

d) Options a, b and c are correct.

2. To this date, the only etiologic agent of leprosy is M. leprae.

a) The sentence is correct;

b) The sentence is incorrect;

c) M. scrofulaceum can also cause leprosy;

d) M.violaceum can also cause leprosy.

3. Indeterminate patients represent the larger number in all health care facilities that regularly examine contacts and school-aged individuals.

a) Correct;

b) Incorrect;

c) As opposed to what was stated, there is predominance of lepromatous forms;

d) As opposed to what was stated, there is predominance of borderline-lepromatous forms.

4. Indeterminate leprosy is characterized by hypopigmented lesions, in a variable number. The presence of erythema and well-defined borders almost always indicate:

a) Evolution to other clinical forms of leprosy;

b) Tendency to chronicity of the disease and persistence as indeterminate;

c) Tendency to spontaneous regression;

d) In general, this evolutional aspect indicates a diagnostic error.

5. One of the important clinical features of borderline-borderline leprosy is:

a) Constant presence of erythematous nodes;

b) Presence of plaques with apparently spared central areas;

c) Presence of diffuse, universal infiltration;

d) All are incorrect.
6. In borderline-tuberculoid leprosy, one can observe:

a) Always positive bacilloscopy;

b) Always negative bacilloscopy;

c) Bacilloscopy can be positive; usually, there is reduced number of bacilli;

d) Severe nerve lesions are rarely seen if the patient is not adequately treated.

7. Reactions in borderline patients can be severe and lead to:

a) Visceral lesions in almost all patients;

b) Lagophthalmos, wrist drop, claw hand and extremely severe liver lesions;

c) Foot drop and plantar trophic ulcers in long-standing cases without adequate treatment;

d) All are incorrect.

8. Select the correct option:

a) Erythema nodosum is part of the type I reactions, being more common in borderline-borderline patients;

b) During type I reactions, ulcerated erythema nodosum is the predominant clinical picture of lepromatous leprosy patients, Lúcio-Alvarado type;

c) There is no ulceration of the cutaneous lesions in type I reaction;

d) As opposed to Lúcio's phenomenon, ulcerated cutaneous lesions in type I reactions do not present with a histopathology of vasculitis.

9. The diagnosis of leprosy is, in the majority of cases, clinical and epidemiological; it is based mainly on the dermatological and neurological examination. Testing for temperature, pain and touch sensation is important for clinical diagnosis; however, many lesions of the indeterminate and multibacillary forms can present with normal sensation, and can actually be painful during reactions.

a) True;

b) False;

c) Diagnostic confirmation will always depend on PCR;

d) Diagnostic confirmation will always depend on PGL-1 serology.

10. According to the WHO, an individual is considered a leprosy patient when:

a) Present with erythematous macules or plaques on the skin, reduced or absent sensation, numbness or tingling sensation of the hands and feet;

b) Stength reduction in hands, feet or eyelids; painful or thickened nerves;

c) Edema or nodules on the face or earlobes; painless wounds or burns on hands and feet;

d) All three are correct. 
11. Reduction or loss of temperature, pain and touch sensation are fundamental for the clinical diagnosis of leprosy. However, many of the indeterminate and multibacillary forms can present with normal sensation, and can actually be painful during reactions. In these cases, the following complementary tests are important:

a) Bacilloscopy is never necessary;

b) Histopathology, histamine test, pilocarpine test, IgM antibodies against PGL-I, PCR, Ultrasound or magnetic resonance of nerve trunks, depending on the clinical picture;

c) All cases of leprosy, reaction and recurrence, can be safely diagnosed with no laboratory tests;

d) All options are incorrect.

12. In $2015,210,758$ new cases of leprosy were detected in the world, corresponding to a detection coefficient of 3.2 cases per 100,000 inhabitants and prevalence of $0.29 / 10,000$ inhabitants. Of the total of new cases detected in the world, $8.9 \%$ were younger than 15 years of age; in Brazil, $4.46 \%$ of the new cases were younger than $\mathbf{1 5}$ years of age. Choose the correct option:

a) 2015 data indicate that the elimination goal of leprosy was not achieved:

b) Considering the low coefficient of global leprosy detection and that less than $10 \%$ of these cases were seen in children, we can conclude that this disease is not an important public health problem;

c) The high proportion of new cases of leprosy in patients younger than 15 years of age indicates that disease transmission continues in the community;

d) All options are incorrect

13. After introducing MDT and reducing treatment duration for patients, a marked reduction in leprosy prevalence was observed. Choose the correct option:

a) MDT regimen impacted in leprosy transmission. The main consequence was the prevalence reduction;

b) MDT regimen is not effective and did not impact as expected in leprosy transmission;

c) Training of health professionals for early case detection, associated to research for better understanding of the transmission are needed to interrupt leprosy transmission;

d. None of the options are correct.
14. The combination of drugs MDT or PQT, recommended by WHO in 1981, includes dapsone, rifampicin and clofazimine. This therapeutic regimen, effective for treatment and drug resistence prevention, was responsible for the reduction in leprosy prevalence. Select the correct option:

a) $\mathrm{MB}$ treatment has been changing in regards to administration course: initially, until bacilloscopy became negative; then, 24 doses and, lastly, 12 months. According to recent research, there is a possibility of treatment reduction to six months in all leprosy clinical forms;

b) Regardless of treatment duration, efficacy results are similar;

c) For children, the therapeutic regimen is the same, with different dosing;

d) All options are correct.

15. Uniform regimen (U-MDT) for PB and MB patients, without the need of clinical or laboratory classification for treatment purposes, has been studied since 2003. Select the correct option:

a) It is about using six doses of the same therapeutic regimen for all patients, regardless of the number of lesions, clinical form or reactions;

b) Studies conducted in India and China indicate that the uniform regimen for pauci and multibacillary promoted clinical improvement of skin lesions, was effective for $\mathrm{PB}$ and $\mathrm{MB}$ and would be feasible to implement in health care services;

c) Recent studies conducted in Brazil confirmed results from other countries. Besides, this investigation allows to conclude that the uniform treatment, with six months duration for PB and $\mathrm{MB}$ patients, regardless of the classification, can be recommended for leprosy control programs;

d) All sentences are correct.

16. Results from a randomized, controlled clinical trial performed in Brazil, with a long patient follow-up to evaluate the efficacy of uniform therapeutic regimen in leprosy patients (U-MDT/CT-BR), showed that:

a) In regards to efficacy, there was no statistical difference between the groups that received treatment with 12 doses of MDT and those that received six doses;

b) Introduction of clofazimine in the treatment of PB patients did not negatively impact in patient satisfaction;

c) Adverse effects seen among U-MDT patients are similar to those seen with the current 12-dose regimen, therefore, the uniform regimen is safe and can be implemented in all levels of the health system;

d) All options are correct 
17. Current leprosy leprosy, regardless of the duration, has been shown to be extremely effective. However, the incidence of reactions remains almost unchanged. Choose the correct option:

a) Iirregular treatment, especially inthe monthly doses, is among the most important causes for this occurrence;

b) Persistence of bacilli residues for many years would be one of the main reactions causes;

c) Reactions depend on the immunologic relationship between host and parasite, that determines the frequency and severity of the reaction;

d) Options b and c are correct.

\section{Choose the correct option:}

a) Despite the excellent results of current therapeutical regimens, we are still distant from a reduction in leprosy transmission ;

b) Presence of persistent bacilli is extremely important for recurrences development;

c) All current therapeutic regimens have side effects that, in practice, hinder large scale treatment;

d) Drug resistance is higher than $20 \%$.
19. Choose the correct option:

a) The diagnosis of new patients with disabilities does not indicate late diagnosis;

b) Programs that have high rates of MB patients among the new cases probably need to reassess control strategies, particularly those related to early diagnosis;

c) Programs with high rates of PB patients among the new cases do not necessarily need to reassess control strategies, particularly those related to early diagnosis;

d) All options are incorrect.

20. In order to achieve reduction in leprosy transmission, we need:

a) Good structure for the control programs and adequate training of health care professionals, including in universities;

b) Short duration treatment regimens;

c) In the future, the vaccination and probably prophylactic treatment;

d) All options are correct.

\section{Answer key}

Sporotrichosis: An update on epidemiology, etiopathogeny, laboratory and clinical-therapeutics. An Bras Dermatol. 2017;92(5): $606-20$.

\begin{tabular}{llll}
\hline 1. $\mathrm{A}$ & 6. C & 11. $\mathrm{D}$ & $16 . \mathrm{B}$ \\
2. C & 7. $\mathrm{B}$ & $12 . \mathrm{C}$ & $17 . \mathrm{D}$ \\
3. $\mathrm{D}$ & 8. $\mathrm{B}$ & $13 . \mathrm{C}$ & $18 . \mathrm{C}$ \\
4. $\mathrm{D}$ & $9 . \mathrm{C}$ & $14 . \mathrm{A}$ & $19 . \mathrm{A}$ \\
5. C & $10 . \mathrm{B}$ & $15 . \mathrm{C}$ & $20 . \mathrm{C}$ \\
\hline
\end{tabular}

\section{Papers}

Information for all members: The EMC-D questionnaire is now available at the homepage of the Brazilian Annals of Dermatology: www.anaisdedermatologia.org.br. The deadline for completing the questionnaire is 30 days from the date of online publication. 